\title{
Surface modification of fumed silica by photo-dimerization reaction of cinnamyl alcohol and cinnamoyl chloride
}

\author{
Aki Kawamura ${ }^{\text {a }}$, Haijing Liu ${ }^{\text {a, b }}$, Chika Takai ${ }^{\text {a }}$, Takashi Takei ${ }^{c}$, Hadi K. Razavi ${ }^{\text {a }}$, \\ Masayoshi Fuji ${ }^{\text {a }}$ * \\ ${ }^{a}$ Advanced Ceramics Research Center, Nagoya Institute of Technology,
} Honmachi 3-101-1, Tajimi, 507-0033 Japan

TEL: $+81-572-24-8110$

FAX: +81-572-24-8109

${ }^{\mathrm{b}}$ Electrochemical Process and Technology for Materials, Beijing University of Chemical Technology

15 Beisanhuan East Road, Chaoyang District, Beijing, China, 100029

${ }^{c}$ Faculty of Urban Environmental Sciences, Tokyo Metropolitan University,

1-1 Minamiohsawa, Hachioji, Tokyo 192-0397, Japan

*Corresponding author: fuji@nitech.ac.jp 
Abstract

The surface modification of silica particles by an organic functional group has been intensively studied, and the modified structure can be analyzed by various experiments and simulations. Cinnamyl alcohol and cinnamoyl chloride are well known for their photo-dimerization reactions. By introducing them on the fumed silica surface, it is possible to create a functional silica which can be aggregated by cross-linking under optical irradiation. For surface modification of the fumed silica, an autoclave method was used with the cinnamyl alcohol, while the reflux method was used for the cinnamoyl chloride. Fourier Transform Infrared Spectroscopy (FT-IR), a thermogravimetric analysis (TG) and the Bruneuer-Emmett-Teller (BET) method were used to evaluate the surface structure of the modified silica. In the case of modification with cinnamyl alcohol, the maximum amount of the modifier groups was $1.7-\mathrm{OR} / \mathrm{nm}^{2}$, and the modification degree could be controlled by varying the initial concentration of the modifier in the reaction. On the other hand, the maximum amount of the modifier groups was 0.33 -OR $/ \mathrm{nm}^{2}$ with cinnamoyl chloride, but it could be increased to 0.69 -OR $/ \mathrm{nm}^{2}$ when pyridine was used as the catalyst during the modification. The reaction process was evaluated by the MOPAC simulation, and the ultraviolet (UV) absorption based on the structure was calculated by ZINDO. In the photo-irradiation experiment, which used an extra high pressure mercury lamp as a spectral source, it was confirmed that the modifier on the silica surface formed $\alpha$ and $\beta$-dimer, the structure of which was decided by the intermolecular distance. In this study, it was 
confirmed that the cross-linking occurs on interparticle based on the results of the simulation and measurement of the UV absorption. However, a moderate density of the modifier is essential for initiating the interparticle cross-linking.

Keywords; silica, surface modification, cinnamyl alcohol, cinnamoyl chloride, optical irradiation 
1. Introduction

In recent years, the $3 \mathrm{D}$ printer has been begun to be used in various fields [1-3]. The $3 \mathrm{D}$ printer could create structures by read out of the three-dimensional data generated by Computer Aided Design (CAD) $[4,5]$. The start of that technology was acquisition of a patent on 3D stereo lithography [6, 7] by Chuck Hull who was an American engineer in 1987. His first working 3D printer was created in 1984. He published a number of patents on the concept of 3D printing, many of which are used in today's additive manufacturing processes. [8-10]. In addition to the foregoing, based on the invention of various molding method technologies, Fused Deposition Modeling [11-13], Inkjet [14-17] and Selective Laser Sintering [18-22] are also applied to the 3D printer [23].

Following the evolutional of development of the technology and price reduction of the $3 \mathrm{D}$ printer, the $3 \mathrm{D}$ printer market is rapidly growing. Along with this development, the demands of resins for each manufacturing method have been rapidly rising and technical development has proceeded. A UV curing resin with an acrylic resin base and a thermoplastic resin with an acrylonitrile-butadiene-styrene resin base are primarily used in the 3D printer material. In current industry, based on the inkjet printer becoming mainstream because it can be further reduced in size, the market share growth of UV curing resin is significantly expanding on a global scale [24]. Using the UV curing resin has attracted attention in recent years from the viewpoint of a small environmental burden because it provides reducing the volatile organic compound (VOC) due to its 
instant formation of the cure coating film by UV irradiation [25]. As a conspicuous feature of the UV resin, it doesn't need a drying process for removing the solvent which makes it possible to shorten the working hours.

In the past decade, nanosilica particles have been widely introduced into polymers to provide functionalities which has never existed before [26]. There are some reports that the nanosilica contained in UV cured resin provided new functions for the polymers. Nanosilica particles are used as the filler of UV acrylate paint and it provided the function to crosslink and cure the silica and UV curing resin by UV irradiation [27]. However since the amount of silica powder to be added to a UV resin is limited, it is difficult to obtain a UV resin containig a large amount of the inorganic material. If the material included an inorganic material in greater amount than the organic polymer, the $3 \mathrm{D}$ printing process may be possible to be more environmentally friendly. Additionally, one of the optical shaping methods requires a step of excessive resin removal, thus it can reduce the surplus resin and increase of efficiency due to shorter processing time. If it is possible that the inorganic material can function between itself by photo-irradiation, it can increase its content rate and can function in the polymer.

There are two kinds of photo-dimerization functional groups, which are the cinnamoyl based and cinnamylidene based groups. Many compounds functionalized with these groups, such as activated ethylene and polycyclic compounds, are able to perform the photo-dimerization reaction, developing 
a reaction of the intermolecular cross-linking bond in the polymer. As cinnamoyl groups develop the $[2+2]$ cyclization by the photo-dimerization reaction, polyvinyl cinnamate, which was made by the esterification reaction of the cinnamoyl groups and PVA, becomes insoluble depending on the photo-crosslinking [28]. Therefore, polyvinyl cinnamate applied as the negative photoresist is one of the representative examples of the photo-sensitive resin. Inspired by the photo-reaction of polyvinyl cinnamate, photo-functional groups might be introduced on the surface of the fumed silica, creating functional particles having the properties of photo-crosslinking by optical irradiation, and developing the nano-sized inorganic functional materials which are difficult to be obtained by modern technology $[29,30]$.

Herein, it was introduced that the cinnamoy chloride has a cinnamyl group (C6H5- $\mathrm{CH}=\mathrm{CH}-\mathrm{CH} 2-)$ and cinnamyl alcohol has cinnamoyl group ( $\mathrm{C} 6 \mathrm{H} 5-\mathrm{CH}=\mathrm{CH}-\mathrm{CHO}-)$ on the fumed silica surface because their terminal substituted by $-\mathrm{Cl}$ and $-\mathrm{OH}$ has a high reactivity with the silanol groups. Furthermore, it was determined that the corresponding interparticle photo-dimerization process of the cyclobutane ring formed with the photo-functional groups on the modified silica surface.

\section{Experimental}

2.1 Materials and surface modification

Fumed silica powder, Aerosil@ OX50 (OX50), was obtained from Nippon Aerosil Co., LTD. 
Cinnamyl alcohol and cinnamoyl chloride with photo-functional groups were used as the modifier,

and the physical properties of the two photo-functional groups are shown in Table 1. As both

photo-functional groups can initiate a reaction when exposed to natural light, these experiments were

carefully carried out in the dark. For the surface modification with cinnamyl alcohol, the autoclave

method was performed at $270{ }^{\circ} \mathrm{C}$, and $30 \mathrm{~atm}$ for 1 hour with hexane used as the solvent [31,32]. An

additional amount of modifier was then changed from 0.25 to 20 number of modifiers per $\mathrm{nm}^{2}$ on the

modified silica surface related to the specific surface area of $2 \mathrm{~g}$ of OX50. After the reaction, the

sample was dried in a nitrogen atmosphere at above $70^{\circ} \mathrm{C}$. For the modification with cinnamoyl

chloride, the reaction was carried out by the reflux method [33]. OX50 (2.0 g) was dispersed in

$62.5 \mathrm{~mL}$ of hexane and a certain amount of cinnamoyl chloride was then dissolved. The additional

amount of cinnamoyl chloride was changed the same as for the modification using cinnamyl alcohol.

The suspension was heated to reflux for 1 hour at $68^{\circ} \mathrm{C}$, then the modified OX50 was washed with

$80 \mathrm{~mL}$ of hexane 3 times and separated by pressure filtration, followed by drying under reduced

pressure. Surface modification was carried out by the reactions of the cinnamyl alcohol and

cinnamoyl chloride molecules with the hydroxyl groups on the silica surface according to the

following equations:

$$
\begin{aligned}
& \mathrm{C}_{6} \mathrm{H}_{5} \mathrm{CH}=\mathrm{CHCH}_{2} \mathrm{OH} \dashv \mathrm{HO}-\mathrm{Si}-\mathrm{C}_{6} \mathrm{H}_{5} \mathrm{CH}=\mathrm{CHCH}_{2} \mathrm{O}-\mathrm{Si} \equiv \dashv \mathrm{H}_{2} \mathrm{O} \\
& \mathrm{C}_{6} \mathrm{H}_{5} \mathrm{CH}=\mathrm{CHCH}_{2} \mathrm{OCl}+\mathrm{HO}-\mathrm{Si} \rightarrow \mathrm{C}_{6} \mathrm{H}_{5} \mathrm{CH}=\mathrm{CHCH}_{2} \mathrm{O}-\mathrm{Si} \equiv+\mathrm{HCl}
\end{aligned}
$$




\subsection{Characteristics of silica surface}

Qualitative analysis of the modifier on the surface of the modified OX50 was evaluated by FT-IR (Jasco FT/IR-620 spectrometer, Jasco Corporation), and the purpose of this characterization was to determine the decrease in the hydroxyl groups and presence of the Si-O-C spectral peak. It is regarded that the spectral peak of Si-O-C was attributed to chemisorption of the modifier on the silica surface, thus the processing of the modified reaction can be confirmed by observing this peak. The FT-IR measurement was done at a resolution of $4 \mathrm{~cm}^{-1}$ between 400 and 4000 and the scan number was 200. The sample was molded into a pellet and it was then placed in a vacuum measuring cell [34].

The surface modifier density was estimated from the amount of modifiers and the specific surface area. Quantitative analysis of the modifier groups was obtained from the TG/DTA performed using a Rigaku Thermo plus TG8120 (Rigaku Corporation) from $30{ }^{\circ} \mathrm{C}$ to $550{ }^{\circ} \mathrm{C}$ at the heating rate of 20 ${ }^{\circ} \mathrm{C} / \mathrm{min}$ in flowing air at $250 \mathrm{~mL} / \mathrm{min}$.

2.3 Determination of hydrophilic/hydrophobic

In order to determine the hydrophobic or hydrophilic properties of the modified silica surface, the sample powders were dropped into the water, while the floating nature was judged by visual 
observation. The hydrophilic powders sank in the water, while the hydrophobic ones floated [ 35 ,

36].

\subsection{Simulation}

The modified silica forms a dimer structure through the cyclobutane-ring with $\mathrm{C}=\mathrm{C}$ bonds by optical irradiation due to the photo-irradiation reaction described as follows:

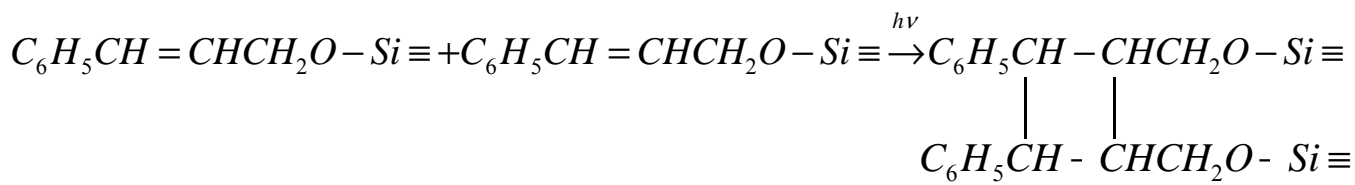

(3)

The, simulation results provided information about the UV absorbing spectrum of the $\alpha$ and

$\beta$-dimer structure of the modifiers by optical irradiation.

This simulation was carried out using the software "CAChe4.4" produced by Fujitsu Limited, and the MP3 method of MOPAC was selected for the structural optimization. In addition, the UV absorption spectrum was calculated by ZINDO which is a semi-empirical quantum chemistry method.

2.5 Optical irradiation and UV spectral characteristics of modified silica surface

2.5.1 Determination of tablet molding condition 
The optimum condition for the tablet molding of the modified silica used in the photo-irradiation experiment was determined by nitrogen adsorption, which could determine the pore sizes within the tablet samples [37].

The nitrogen adsorption measurements were performed using a Gemini manufactured by the Shimadzu Co., Japan. The measurement range of $\mathrm{P} / \mathrm{P}_{0}$ was between 0.7 and 0.99 with plot numbers of 30 . The tablet samples of the silica powder were molded under various pressures, $\left(20,50 \mathrm{kgf} / \mathrm{cm}^{2}\right)$ and not molded.

\subsubsection{Optical reaction of modified silica}

Due to the photo-dimerization of the modifiers, a photoreaction was observed by a UV

spectrometer using a on UV3100PC manufactured by the Shimadzu Corporation during the photo irradiation experiment. An extra high pressure mercury lamp (USHIO) covered with pyrex glass because of lightproof below $300 \mathrm{~nm}$ was selected as the optical source. The following are the other optical irradiation conditions: distance between the sample and optical source was $80 \mathrm{~cm}$, the wattage was $350 \mathrm{~W}$ and the wavelength band emission was $300 \mathrm{~nm}$ to $500 \mathrm{~nm}$. Acetonitrile and hexane were used as the solvents of the modifiers. On the other hand, when characterizing the surface modified silica, samples were formed into tablets which was confirmed to form the $\alpha$ bridge between the particles and measured by the diffuse reflex method. 
3. Results and discussion

\subsection{Characteristics of fumed silica}

The corresponding transmission electron microscope (TEM) image of Aerosil® OX50 is shown in Fig.1. As the sample is nonporous with a smooth surface, it is used to investigate the modified surface structures. The specific surface area of OX50 is $46.9 \mathrm{~nm}^{2}$ measured by the BET method and the density of the surface hydroxyl groups for the unmodified sample was determined to be 3.2 $-\mathrm{OH} / \mathrm{nm}^{2}$ by the Grignard reagent method $[38,39]$.

\subsection{IR spectral characteristics of silica surface}

The IR spectral characteristics of the silica with earlier reported data are shown in Table 2. The FT-IR spectra of the unmodified OX50 and silica particles modified with various concentrations of cinnamyl alcohol are shown in Fig.2 and Fig.3, respectively. Based on the curves, the silica bond absorption at $1868 \mathrm{~cm}^{-1}$ was determined based on the baseline of $2450 \mathrm{~cm}^{-1}$ in each sample. Analyzed from Fig.3, the -CH peak derived from the benzene ring located at $3066 \mathrm{~cm}^{-1}$ gradually increased with the increasing concentration of the cinnamyl alcohol, while the $\mathrm{O}-\mathrm{H}$ stretching and adsorbed water decreased. In addition, the small peak that appeared at $963 \mathrm{~cm}^{-1}$ was assigned to the Si-O-C bond as shown in Fig.4, which is attributed to the chemisorption modifier on the silica surface. It can 
be concluded that the surface modification was successfully performed by the chemical reaction of the cinnamyl alcohol molecules with the surface silanol groups by the autoclave method.

3.3 Determination of modifier introduced on silica surface

The number of modifier groups introduced onto the silica surface $\left(d_{B}\right)$ was calculated using equation (4), applying the weight losses of the modified sample $\left(W_{\mathrm{CH}}\right)$ and unmodified sample $\left(W_{\mathrm{OH}}\right)$.

$$
d B\left(-O R / n m^{2}\right)=\frac{\left(\Delta w_{C H}-\Delta w_{O H}\right) N_{A}}{M_{W} S_{N 2}} \times 10^{18}
$$

where $\Delta W_{\mathrm{CH}}$ and $\Delta W_{\mathrm{OH}}$ are the ratio of the weight loss for the modified and unmodified samples, respectively, measured by TG, $M_{W}$ is the molar weight of the modifier groups, $S_{\mathrm{N} 2}$ is the BET specific surface area measured from the nitrogen adsorption isotherm, and $\mathrm{N}_{\mathrm{A}}$ is Avogadro's number [35].

The TG/DTA curves of the unmodified and modified silica were obtained by continuous heating at a definite temperature rate and the results are shown in Fig.5 and Fig.6, respectively. Based on the DTA curve, an exothermic reaction began around $270^{\circ} \mathrm{C}$, indicating that the burning of the modifier on the silica surface began at this temperature. Therefore, the amount of modifiers can be estimated 
from the weight loss in the TG curve in the combustion region of $270-550{ }^{\circ} \mathrm{C}$, which was determined by the DTA curve. In the case of the cinnamyl alcohol modified silica, the maximum surface density of the functional groups is $1.7-\mathrm{OR} / \mathrm{nm}^{2}$, and the relationship between the cinnamyl alcohol amount for the sample weight and surface density of the modification group is shown in Fig.7. Meanwhile, two samples, which were modified with 0.44 and $3.23 \mathrm{~mL} / \mathrm{g}$ cinnamyl alcohol, were used for the optical irradiation examination.

On the other hand, the maximum surface density of the modifier group was about $0.33-\mathrm{OR} / \mathrm{nm}^{2}$ for the samples modified with cinnamoyl chloride by the reflux method, while the value can be increased to $0.69-\mathrm{OR} / \mathrm{nm}^{2}$ with pyridine as the catalyst.

\subsection{Determination of hydrophilic/hydrophobic}

The unmodified silica sank in the water due to its hydrophilicity, while the modified sample floated on the water because of its hydrophobicity. The hydrophobic propensity was observed in a sample with the modifier density of $1.0-\mathrm{OR} / \mathrm{nm}^{2}$, and a higher density still lead to the surface hydrophobicity. Based on these results, it is postulated that the surface of the silica was uniformly-modified by the cinnamoyl groups at a modifier density greater than $1.0-\mathrm{OR} / \mathrm{nm}^{2}$ [44]. 
The intermolecular distance was calculated assuming that the modifiers were present in the most densely packed state on the silica surface. Their formulas and image diagrams are shown in Fig.8. The intermolecular modifier distance for the sample with the surface density of $1.8-\mathrm{OR} / \mathrm{nm}^{2}$ was calculated to be about $0.75 \mathrm{~nm}$, while the value for the sample with $0.4-\mathrm{OR} / \mathrm{nm}^{2}$ was about $16 \mathrm{~nm}$. According to the established topo chemistry concept by Schmidt et al., the reactive double bonds are located parallel and the minimum distance between each other is $0.36-0.42 \mathrm{~nm}$ in the photodimerized olefin crystal [45]. Taking their concept into account, the dimers could not be formed in the calculated intermolecular distance. However, this calculation result was just an average distance determined from the surface modification density. It is considered that the surface modifiers are not evenly distributed and some modifiers might actually exist closely-situated on the silica surface, which could possibly initiate the photo-dimerization.

\subsection{Simulation}

The structures of the monomer and $\alpha, \beta$-photodimers for the cinnamyl alcohol are shown in Fig.9, and it is considered that the $\alpha$-dimer possibly formed interparticles whereas the $\beta$-dimer formed intraparticles. The UV absorption spectra for each structure of the cinnamyl alcohol and cinnamoyl chloride are shown in Fig. 10 and Fig. 11 respectively. Based on the results of these simulations, the maximum absorption was observed around $250 \mathrm{~nm}$ on both modifiers. However, as these strong 
absorptions were observed on each monomer, these absorptions were not observed after formation of their dimers. It is postulated that for the monomer structure, the $\pi$-electron delocalization occurs on the benzene through the double bond of the alkene on the monomer structure. On the other hand, because the alkene double bond disappears due to the formation of the cyclobutane ring, the $\pi$-electron is partially delocalized in the benzene. Additionally, the difference in the $\alpha, \beta$-dimers is mainly for the adsorption peaks located at $200 \mathrm{~nm}$, that is, the absorption around $200 \mathrm{~nm}$ decreased if the $\alpha$-dimer is formed, while it increased if the $\beta$-dimer is formed.

\subsection{Optical irradiation}

Fig. 12 shows the changes in the UV-absorption spectrum of the modifier in the organic solvent during the optical irradiation. It was observed that the $250 \mathrm{~nm}$ absorption decreased, which is in accordance with the simulation, suggesting that the modifier on the silica surface formed a photo-dimer by optical irradiation.

The pore size results of the tableting samples were provided by nitrogen adsorption, thus it could be assumed how densely the silica particles were packed within each tablet. It is known that the initial pressure of the capillary condensation changes depending on the pose size of the tablet when measuring the nitrogen adsorption, and there is a correlation between the relative pressure at the beginning of the capillary condensation and radius of the capillary evaporation (kelvin radius), $\mathrm{r}_{\mathrm{k}}$. 
The Kelvin radius, $\mathrm{r}_{\mathrm{k}}$, is obtained by Kelvin's equation (5).

$$
\mathrm{r}_{\mathrm{k}}(\AA)=-(2 \gamma \mathrm{Nm} \cos \theta) /\left\{\mathrm{RT} \ln \left(\mathrm{P} / \mathrm{P}_{0}\right)\right\}
$$

where $\mathrm{P}$ is the actual vapor pressure, $\mathrm{P}_{0}$ is the saturated vapor pressure, $\gamma$ is the surface tension, $\mathrm{V}_{\mathrm{m}}$ is the molar volume of the liquid, $\mathrm{R}$ is the universal gas constant, $\theta$ is the contact angle, and $\mathrm{T}$ is temperature. The thickness of nitrogen multilayer has been reported by many researchers $[46,47]$. Herein, the experimentally resolved multilayer thickness was calculated by formula (6) which was reported by Makinshima et al. using the Cranston-Inkley method.

$$
\mathrm{t}=2.633+11.87 \chi-46.68 \chi^{2}-385.8 \chi^{3}+970.8 \chi^{4}-1024.8 \chi^{5}+395.9 \chi^{6}
$$

where $t$ is the multilayer thickness and $\mathrm{x}$ is the relative pressure $\left(\mathrm{P} / \mathrm{P}_{0}\right)$. Based on these formulas, the pore size was calculated and the tableting condition determined [48, 49]. Based on the adsorption isotherm by nitrogen adsorption shown in Fig.13, the capillary condensation began at about 0.995 $\mathrm{P} / \mathrm{P}_{0}$ in the tableting sample shape molded at $50 \mathrm{kgf} / \mathrm{cm}^{2}$.

The $\mathrm{r}_{\mathrm{k}}=207 \AA$ and $\mathrm{t}=14.3 \AA$ were calculated by the kelvin equation, and $\mathrm{r}_{\mathrm{p}}=221.3 \AA$ was determined from sum of $r_{k}$ and $t$. Hence, it was found that the pore radius of pore in the $50 \mathrm{kgf} / \mathrm{cm}^{2}$ tablet sample was about $22 \mathrm{~nm}$ and such a sample has a moderate-density for the optical irradiation experiment. Therefore, it was expected that the modifiers on the silica surface are situated within a reasonable distance to form the $\alpha$-bridge between each other by applying the $50 \mathrm{kgf} / \mathrm{cm}^{2}$ pressure. 
-OR/nm ${ }^{2}$ shown in Fig.14 and 1.8 -OR/nm² shown in Fig.15. Based on, the optical reaction rate of $1.8-\mathrm{OR} / \mathrm{nm}^{2}$ was lower than the $0.4-\mathrm{OR} / \mathrm{nm}^{2}$ sample, although the UV absorption was stronger.

Additionally, the unmodified silica is not a UV absorber. It is expected that the surface modifier of the modified silica could react under optical irradiation and the reaction rate was determined by the modification density amount on the silica surface.

Also, in the case of the simulation result, the decrease in the adsorption at $250 \mathrm{~nm}$ can be observed due to the disappearance of the $\mathrm{C}=\mathrm{C}$, therefore, the optical-dimer was formed on both modified sample surfaces in this experiment. In addition, in the $1.8-\mathrm{OR} / \mathrm{nm}^{2}$ case, it is expected that a large volume of $\beta$-dimers will be formed as analyzed from the increase in the adsorption at $200 \mathrm{~nm}$. On the other hand, in the case of $0.4-\mathrm{OR} / \mathrm{nm}^{2}$, the $\alpha$-dimers would be more easily formed than the $\beta$-dimers judging from the intermolecular distance. For the reasons noted above, if the $\beta$-dimers were formed on the silica surface, the modifier needs to be densely situated because they form intraparticles with the intermolecular distance of $7 \AA$. Moreover, the $\alpha$-dimers are mainly formed between different particles with the intermolecular distance of about $16 \AA$. For these reasons, it is suggested that the surface modifier with a concentration of $1.8-\mathrm{OR} / \mathrm{nm}^{2}$ were densely packed, thus the $\beta$-dimers were easily formed. The surface modifier with a concentration of $0.4-\mathrm{OR} / \mathrm{nm}^{2}$ was situated with enough space in the interparticles, leading to the tendency to form $\alpha$-dimers. Based on these results, it was found that the modification with optical functional groups on the silica surface 
was achieved which lead to the interparticle cross-linking.

\section{Conclusion}

In the present study, it was found that the surface modification density could be controlled by changing the initial concentration of the cinnamyl alcohol by the autoclave method, and the maximum modification density was $1.8-\mathrm{OR} / \mathrm{nm}^{2}$. For the modification with cinnamoyl chloride, the density highly depended on the presence of a catalyst. In this case, the maximum modification density was only $0.33-\mathrm{OR} / \mathrm{nm}^{2}$, but can be increased to $0.69-\mathrm{OR} / \mathrm{nm}^{2}$ with pyridine as the catalyst. Moreover, $\alpha$ and $\beta$-dimers were formed by photo reaction of the surface cinnamoyl groups on these modified silicas. The structure of the dimer on the modified silica surface was mainly affected by the surface modification density, which can be interpreted as the intermolecular distance. If the surface modification density is high, the surface cinnamoyl groups are close to each other, then it could form $\beta$-dimers. In contrast, if the surface modification density is low, enough space between the surface cinnamoyl groups could be created and it could be a better situation to form the $\alpha$-dimers. It was suggested that the formation of $\alpha$-dimers was necessary to form the three dimensional structures.

However, the surface modifiers on the silica surface should not be densely packed for forming the $\alpha$ bridge within the interparticles. 


\section{Acknowledgments}

The deepest appreciation goes to Dr. Masatoshi Chikazawa, the emeritus professor of Tokyo Metropolitan University whose significant support and insightful comments were invaluable during the course of this study. I would also like to thank Mr. Yoshiyuki Yamaokain who provided technical help and sincere encouragement. A part of this study was supported by the Advanced Low Carbon Technology Research and Development Program (ALCA) of the Japan Science and Technology Agency (JST).

References

[1] S. Bose, S. V,Amit B, Bone tissue engineering using 3D printing, Materials Today, 16 (2013) 496-504.

[2] L. S. Dimas, G. H. Bratzel, I. Eylon, M. J.,Buehler, Tough Composites Inspired by Mineralized Natural Materials: Computation, 3D printing, and Testing, Dimas, Advanced Functional Materials, 23 (2013) 4629-4623.

[3] T. Yoshimura, M. Yoshimura, Design and creation of a molecular model for a 3D printer, Journal of Technology and Education, 21 (2014) 9-16.

[4] B. Berman, 3-D printing: The new industrial revolution, Business Horizons 55 (2012) 155-162.

[5] D. T. Pham, R. S. Gault, A comparison of rapid prototyping technologies, International Journal of 
Machine Tools \& Manufacture, 38 (1998) 1257-1287.

[6] F. Doreau, C. Chaput, T. Chartier, Stereolithography for manufacturing ceramic parts, Advanced Engineering Materials, 2 (2000) 493-496.

[7] T. Chartier, C. Chaput, F. Doreau, M. Loiseau, Stereolithography of structural complex ceramic parts, Journal of Materials Science, 37 (2002) 3141-3147.

[8] C. W. Hull, (Uvp, Inc.) US4475330A 1986.

[9] C. W. Hull, (3D Systems, Inc.) US4929402A 1990.

[10] C. W. Hull, (Uvp, Inc.) US5569431A 1996.

[11] I. Zeina, D. W. Hutmacherb, K. C. Tanc, S. H. Teoha, Fused deposition modeling of novel scaffold architectures for tissue engineering applications, Biomaterials, 23 (2002) 1169-1185.

[12] D. W. Hutmacher, T. Schantz, I. Zein, K. W. Ng, S. H. Teoh, K. C. Tan, Mechanical properties and cell cultural response of polycaprolactone scaffolds designed and fabricated, Journal of Biomedical Materials Research, 55 (2011) 203-216.

[13] S. H. Ahn, M. Michael, D. Odell, S. Roundy, P. K. Wright, Anisotropic material properties of fused deposition modeling ABS, Rapid Prototyping Journal, 8 (2002) 248-257.

[14] Mott, M. and Evans, J. R. G., Zirconia/alumina functionally graded material made by ceramic ink jet printing, Mater. Sci. Eng., 1999, A271, 344-352.

[15] E. Oezkol, J. Ebert, A. M. Waetjen, K. Uibel, R. Telle, Development of high solid content 
aqueous 3Y-TZP suspensions for direct inkjet printing using a thermal inkjet printer, Journal of the European Ceramic Society, 29 (2009) 403-409.

[16] X. Zhao, J. R. G. Evans, M. J. Edirisinghe, Song, J. H., Direct ink-jet printing of vertical walls, Journal of the American Ceramic Society, 85 (2002) 2113-2115.

[17] R. Noguera, M. Lejeune, T. Chartier, 3D fine scale ceramic components formed by ink-jet prototyping process, Journal of the European Ceramic Society, 25 (2005) 2055-2059.

[18] J. Guenster, A. Gahler, J. G. Heinrich, Rapid prototyping of ceramic components. Ceramic Forum International, 83 (2006) 53-56.

[19] J. M. Williamsa, A. Adewunmib, R. M. Scheka,c, C. L. Flanagana, P. H. Krebsbacha,c, S. E. Feinbergd, S. J. Hollistera,b,e, S. Das, Bone tissue engineering using polycaprolactone scaffolds fabricated via selective laser sintering, Biomaterials 26 (2005) 4817-4827.

[20] D. L. Bourell, H. L. Marcus, J.W. Barlow, J. J. Beaman, Selective laser sintering of metals and ceramics, International Journal of Powder Metallurgy, 28 (1992) 369-381

[21] H. Exner, L. Hartwig, H. Streek, M. Horn, S. Kloetzer, R. Ebert, R. et al., Laser micro sintering of ceramic materials. Ceramic Forum International, 63 (2006) 44-52.

[22] R. Lenk, A. Naagy, H. J. Richter, A. Techel, Material development for laser sintering of silicon carbide. Ceramic Forum International, 83 (2006) 41-43.

[23] A. M. Waetjen, D. A. Polsakiewicz, I. Kuhl, R. Telle, H. Fischer, Slurry deposition by airbrush 
for selective laser sintering of ceramic components, Journal of the European Ceramic Society 29 (2009) 1-6.

[24] P. Calvert, Inkjet Printing for Materials and Devices, Chemistry of Materials, 13 (2001) 3299-3305.

[25] F. Bauer, R. Flyunt, K. Czihal, H. Langguth b, R. Mehnert, R. Schubert, M. R. Buchmeiser, UV curing and matting of acrylate coatings reinforced by nano-silica and micro-corundum particles, Progress in Organic Coatings 60 (2007) 121-126.

[26] G. Chen, S. Zhou, G. Gu, H. Yan, L. Wua, Effects of surface properties of colloidal silica particles on redispersibility and properties of acrylic-based polyurethane/silica composites, Journal of Colloid and Interface Science 281 (2005) 339-350.

[27] Y. Abe, Current Status and Updates on Radiation Curing Resin for Coating Technology, DIC Technical Review, 11 (2005).

[28] K. Saigo, [2+2] Photocyclization and Photoreversion in Polymer Chemistry, Journal of Synthetic Organic Chemistry, Japan, 73 (2015) 1006-1016.

[29] T. Yamaoka, Photosensitive Polymer Materials, Polymers, 35 (1986) 572-575.

[30] K.Akamatsu, T. Koide, Y.kishimoto, M.Takayama, Applied Technology of Photosensitive Resin, Trade ed., CMC Publishing Co., Ltd., 2009.

[31] K. R. Lange, Reactive organic molecules on silica surfaces, Chemistry and Industry, 36 (1969) 
$1273-1274$.

[32] H. Utsugi, Surface modification of oxide powders and the properties of the modified surfaces,

Hyomen, 11 (1973) 591-609.

[33] H. Utsugi, T. Matsuzawa, A. Akashima, Dehydration and Surface-Treatment of Silica Gels with

Alcohols in Hydrocarbons with High Boiling Point by Reflux Method,

Zairyo, 24 (1975) 638-642.

[34] M. Fuji, C. Takai, Y. Tarutani, T, Takei, M. Takahashi, Surface properties of nanosize hollow

silica particles on the molecular level, Advanced Powder Technol, 18 (2007) 81-91.

[35] M. Fuji, S. Ueno, T. Takei, T. Watanabe, M. Chikazawa, Surface structural analysis of fine silica powder modified with butyl alcohol, Colloid and Polymer Science, 278 (2000) 30-36.

[36] H. Utsugi, T. Matsuzawa, A. Akoshima, Surface Properties of Silica Gels Treated with Alcohols in Long Chain Hydrocarbons by Reflux Method, Zairyo, 24 (1975) 643-648.

[37] K. Sing, The use of nitrogen adsorption for the characterisation of porous materials, Colloids and Surfaces A: Physicochemical and Engineering Aspects, 187-188 (2001) 3-9. [38] J.J. Fripiat, J. Uytterhoeven, Hydroxyl Content in Silica Gel “AEROSIL”, J. Phys. Chem. 66 (1962) 800.

[39] T. Kanazawa, M. Chikazawa, T. Takei, K. Mukasa, Surface Chemistry of Powder Particles and Adhesion Phenomenon, Yougyo Kyoukai shi 92 (1984) 654.

[40] T. Oh, C. K. Choi, Comparison between SiOC Thin Films Fabricated by Using Plasma Enhance 
Chemical Vapor Deposition and SiO2 Thin Films by Using Fourier Transform Infrared

Spectroscopy, Journal of the Korean Physical Society, 56 (2010) 1150-1155.

[41] S. K. Parida, S. Dash, S. Patel, B.K. Mishra, Adsorption of organic molecules on silica surface,

Advances in Colloid and Interface Science 121 (2006) 77-110.

[42] T. I. Chun, V. Rossbach, Polymerization of Tetraethoxysilane by Using Remote

Argon/dinitrogen oxide Microwave Plasma, Jurnal of the Korean Society of Dyers and Finishers, 21

(2009) 19-25.

[43] N. Solc, O. Dopfer, Protonated Benzene: IR Spectrum and Structure of C6H7+, Angewandte

Chemie International Edition, 41 (2002) 3628-3631.

[44] M. Fuji, T. Takei, T. Watanabe, M. Masatoshi, Wettability of fine silica powder surfaces

modified with several normal alcohols, Colloids and Surfaces A: Physicochemical and Engineering

Aspects 154 (1999) 13-24

[45] M. Hasegawa, [2+2] Topochemical Photoreaction, Journal of Synthetic Organic Chemistry, Japan, 46 (1988) 767-775.

[46] K. Kaneko, Adsorption of Gasses, Journal of the Japan Society of Colour Material, 67(1994) No.

$2115-123$.

[47] S. Kondo, T. Ishikawa, I. Abe, Chemistry of Adsorption, 2nd ed., Maruzen Co., Ltd., 2006.

[48] F. Ohashi, M. Maeda, M. Suzuki, S. Tomura, M. Okazaki, K. Toriyama, Water Vapor 
Adsorption Properties of Ti-Containing Mesoporous Silica, Journal of the Ceramic Society of Japan 107 (1999) No.9 844-849.

[49] A. Makishima, T. Sasaki, T. Sakaino, Pore Structure of Porous Materials and Adsorption Isotherms, Journal of the Ceramic Association, Japan, 77 (1969) 225-233. 
Table1 Physical properties of cinnamyl alcohol and cinnamoyl chloride

\begin{tabular}{ccc}
\hline Modifier & Cinnamyl alcohol & Cinnamoyl chloride \\
\hline Formula & $\mathrm{C}_{9} \mathrm{H}_{10} \mathrm{O}\left(\mathrm{C}_{6} \mathrm{H}_{5} \mathrm{CH}=\mathrm{CHCH}_{2} \mathrm{OH}\right)$ & $\mathrm{C}_{9} \mathrm{H}_{7} \mathrm{ClO}\left(\mathrm{C}_{6} \mathrm{H}_{5} \mathrm{CH}=\mathrm{CHCOCl}\right)$ \\
\hline Moleculer weight & 134.18 & 166.6 \\
\hline Melting point & $33{ }^{\circ} \mathrm{C}$ & $35-36{ }^{\circ} \mathrm{C}$ \\
\hline Boiling point & $250{ }^{\circ} \mathrm{C}$ & $256-258{ }^{\circ} \mathrm{C}$ \\
\hline Manufacture & $\mathrm{KANTO} \mathrm{CHEMICAL} \mathrm{CO.,INC}$ & KANTO CHEMICAL CO.,INC \\
\hline
\end{tabular}


Table2 IR spectral characteristics of silica

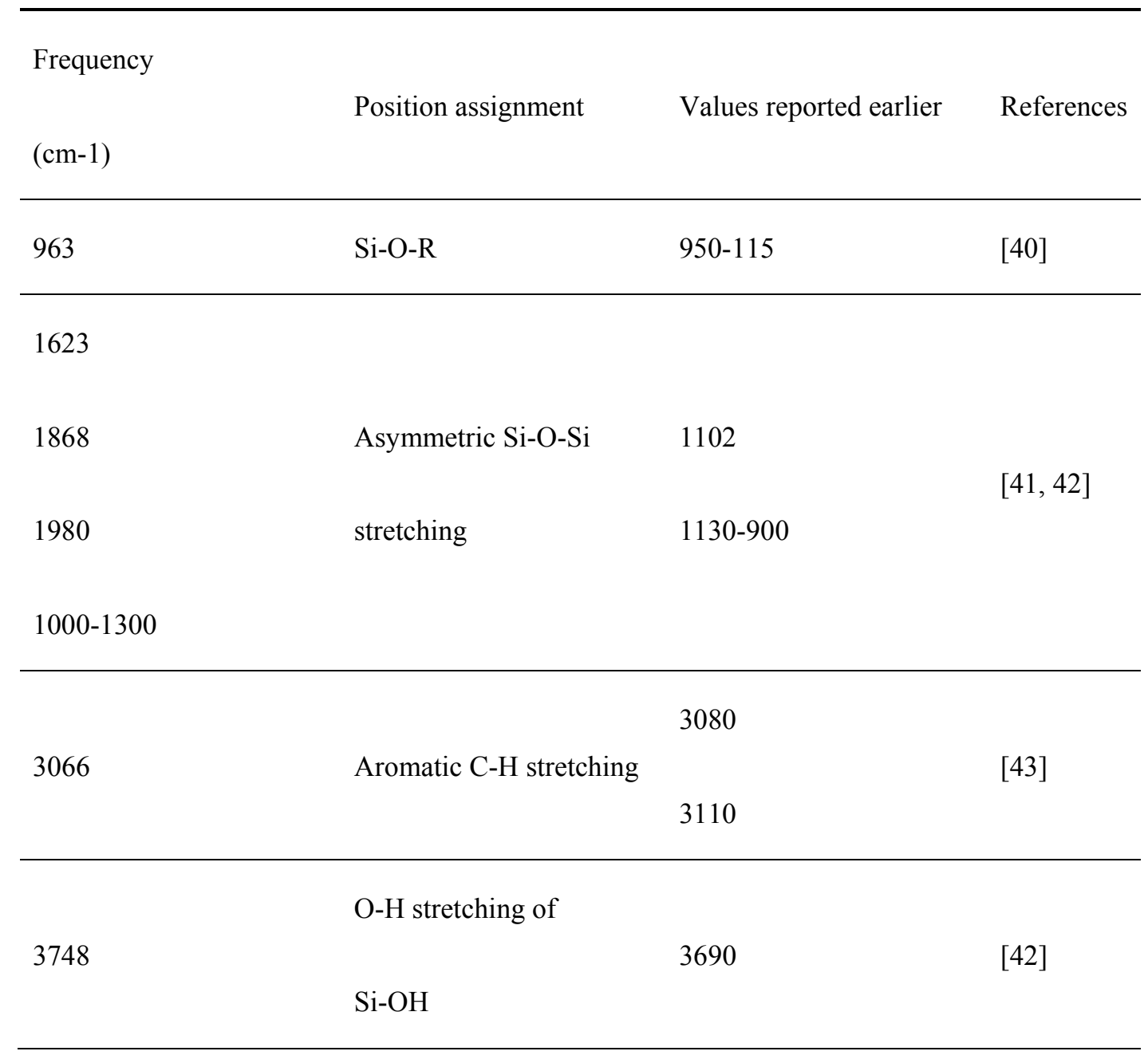




\section{Figure captions}

Fig. 1 TEM image of Aerosil® OX50 obtained in TEM

Fig. 2 FT-IR spectrum of the unmodified silica

Fig. 3 FT-IR spectra of the unmodified and modified silica samples: (a) unmodified cinnamyl

alcohol content was (b) $0.12 \mathrm{~g} / 1$ (c) $0.23 \mathrm{~g} / 1$ (d) $0.44 \mathrm{~g} / 1$ (e) $1.60 \mathrm{~g} / 1$ (f) $2.25 \mathrm{~g} / 1$ (g) $4.46 \mathrm{~g} / 1$

Fig. 4 FT-IR spectrum of Si-O-C at $963 \mathrm{~cm}^{-1}$

Fig. 5 TG/DTA curve for unmodified silica

Fig. 6 TG/DTA curve for modified silica

Fig. 7 Relationship between cinnamyl alcohols contents for sample weight and surface density of

modification groups

Fig. 8 Formulas and image diagram of intermolecular distance of modifiers (The sample whose amounts of surface modifier groups is $1.8-\mathrm{OR} / \mathrm{nm}^{2}$ )

Fig. 9 The structure of monomer and $\alpha, \beta$-dimers of cinnamyl alcohol by simulation

Fig. $10 \mathrm{UV}$ adsorbing spectra of cinnamyl alcohol by simulation

Fig. 11 UV adsorbing spectra of cinnamoyl chloride by simulation

Fig. 12 UV absorbing spectrum change of modifier in organic solvent

Fig. 13 The adsorption isotherm by nitrogen adsorption

Fig. 14 UV absorbing spectrum change of modified sample of $0.4-\mathrm{OR} / \mathrm{nm}^{2}$ modification density 
Fig. $15 \mathrm{UV}$ absorbing spectrum change of modified sample of $1.8-\mathrm{OR} / \mathrm{nm}^{2}$ modification density 


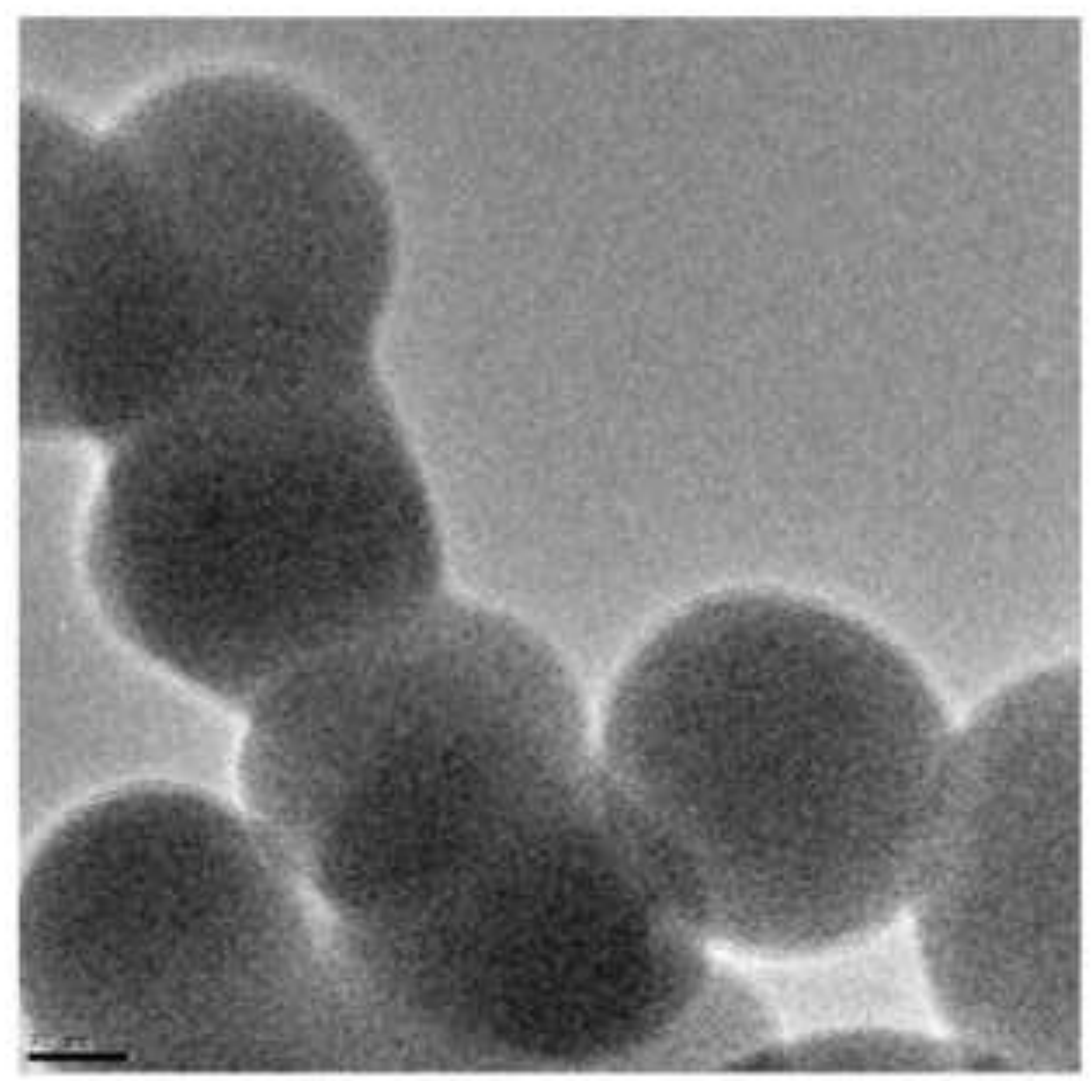

Fig. 1 TEM image of Aerosil $₫$ OX50 obtained in TEM 


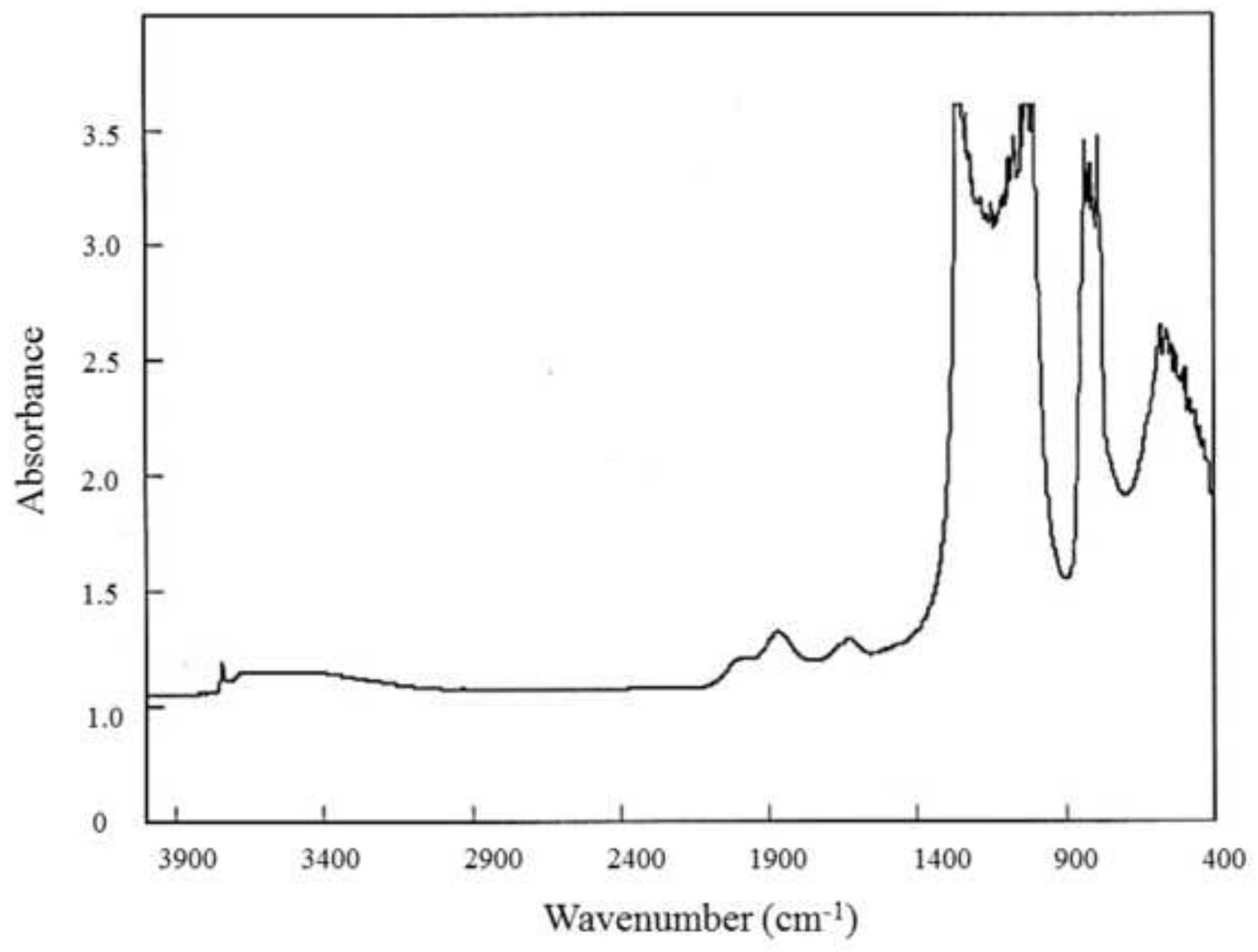

Fig. 2 FT-IR spectrum of the unmodified silica. 


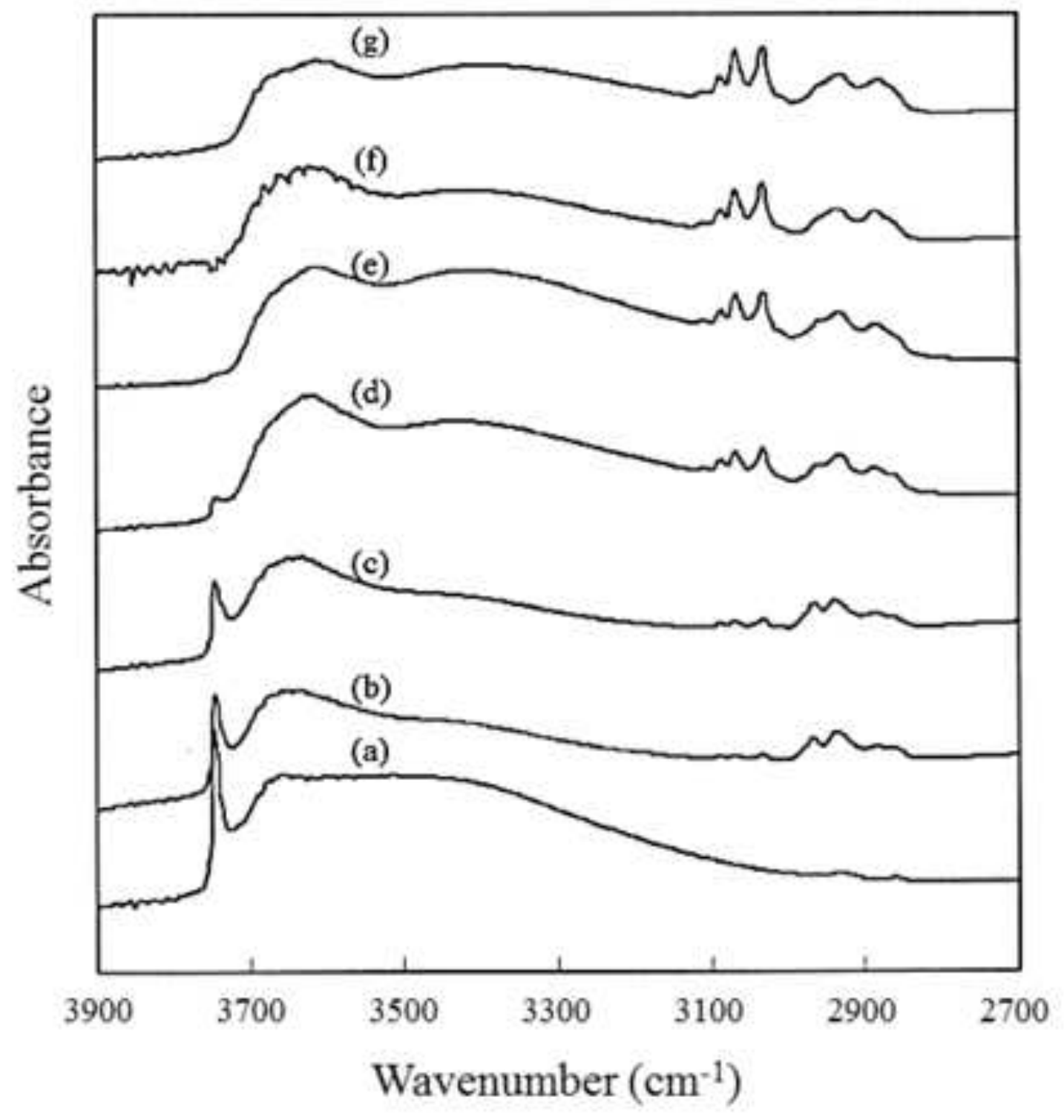

Fig. 3 FT-IR spectra of the unmodified and modified silica samples: (a) unmodified cinnamyl alcohol content was (b) $0.12 \mathrm{~g} / \mathrm{l}$ (c) $0.23 \mathrm{~g} / \mathrm{l}$ (d) $0.44 \mathrm{~g} / 1$ (e) $1.60 \mathrm{~g} / 1$ (f) $2.25 \mathrm{~g} / 1$ (g) $4.46 \mathrm{~g} / 1$. 


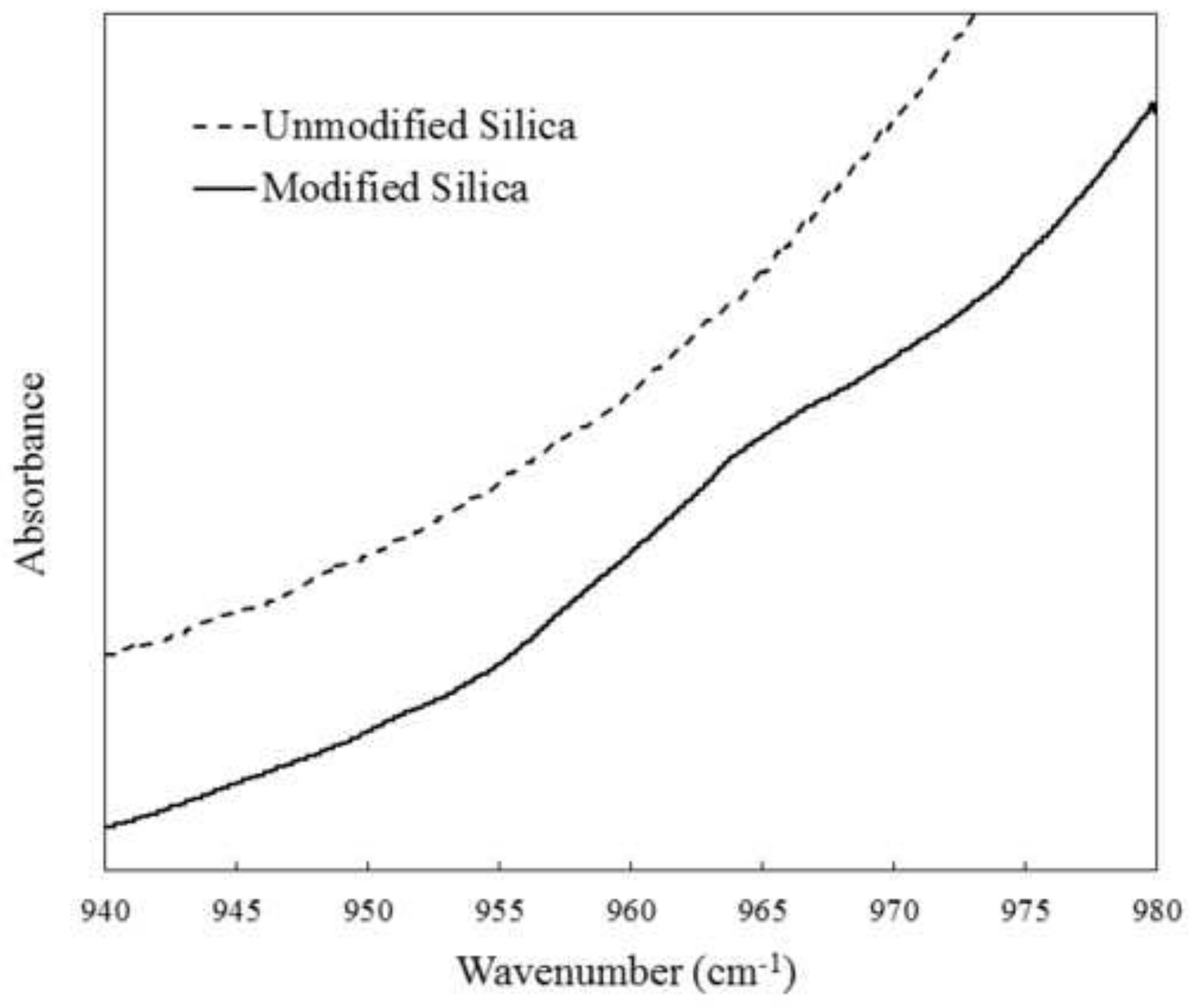

Fig. 4 FT-IR spectrum of Si-O-C at $963 \mathrm{~cm}^{-1}$. 


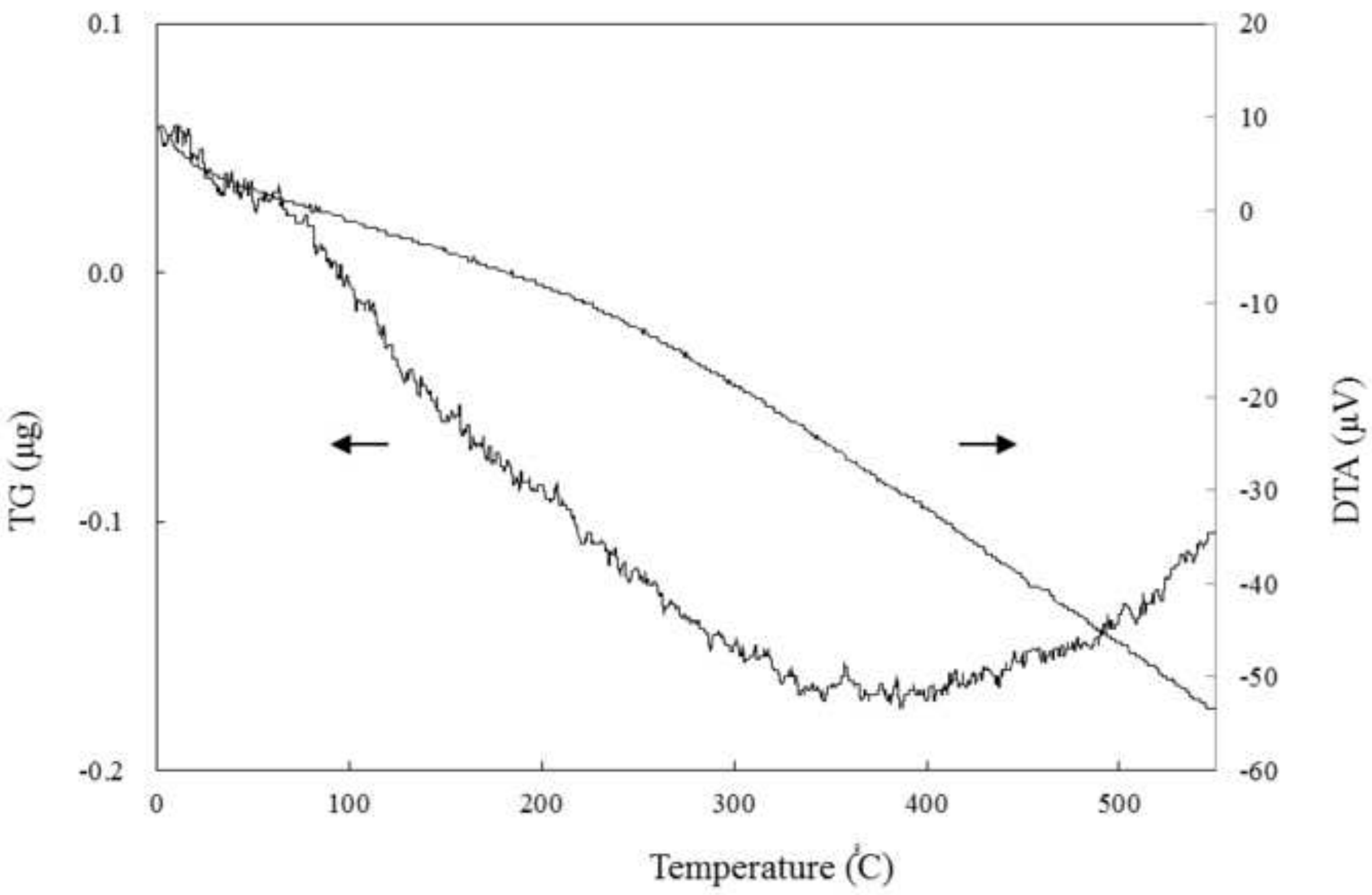

Fig. 5 TG/DTA curve for unmodified silica 


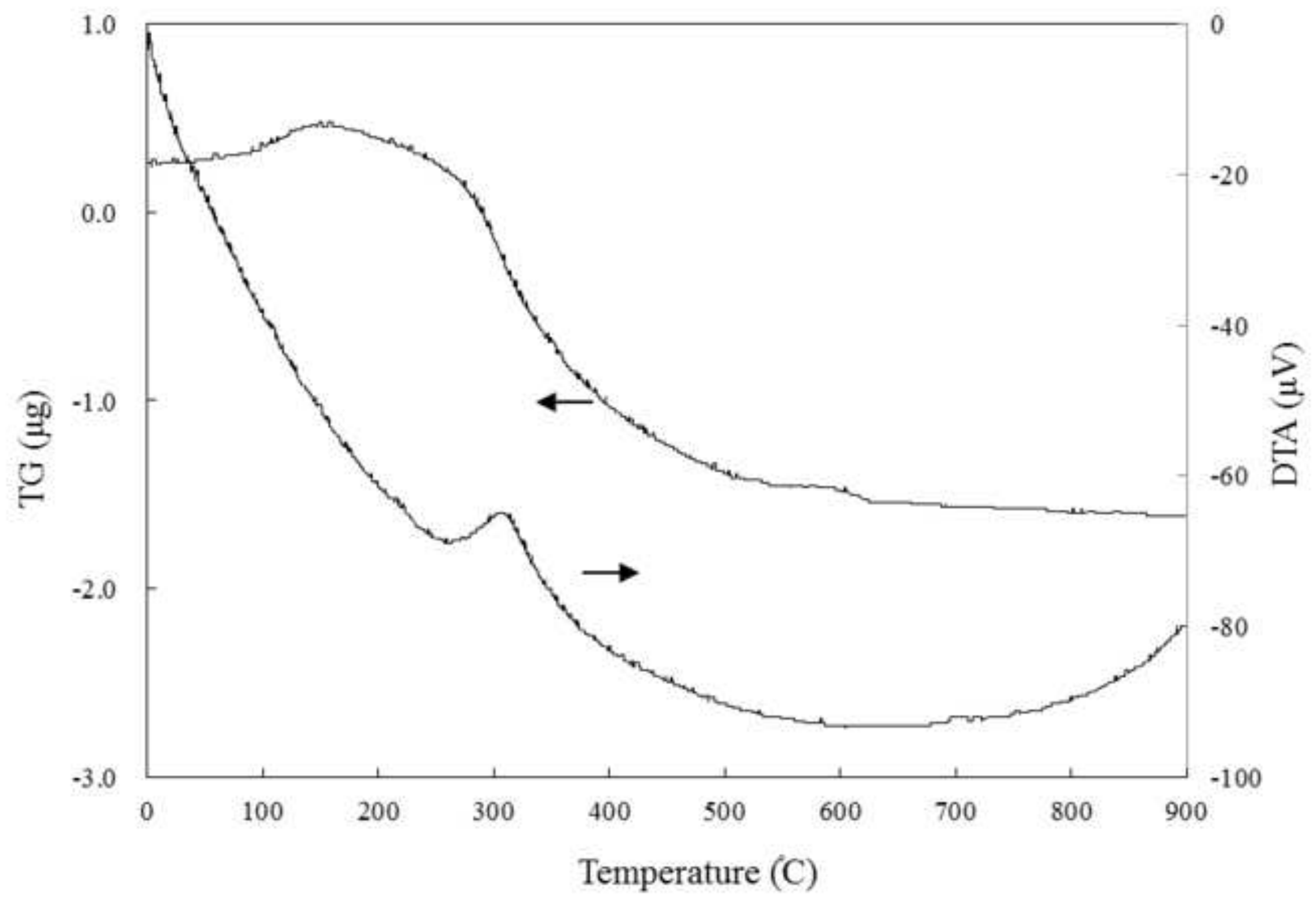

Fig. $6 \mathrm{TG} / \mathrm{DTA}$ curve for modified silica 


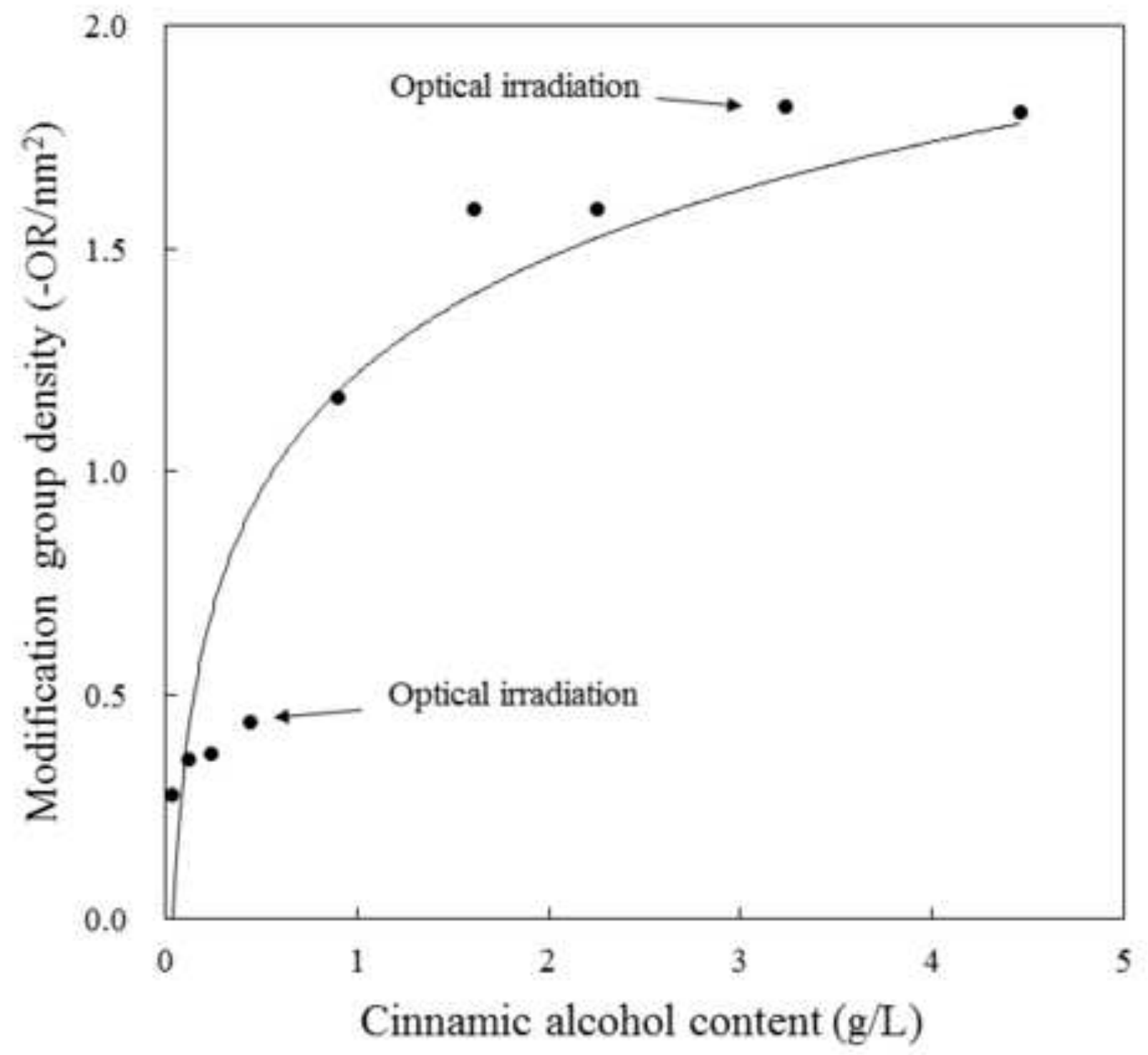

Fig. 7 Relationship between cinnamyl alcohols contents for sample weight and surface density of modification groups. 


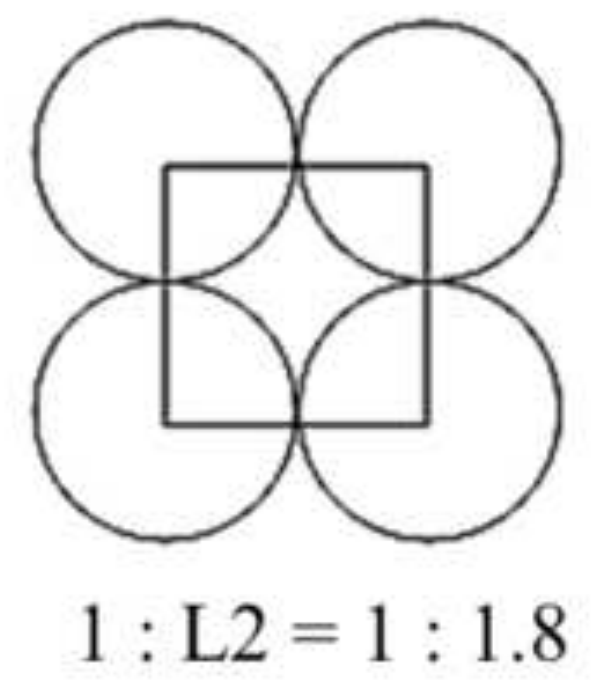

\section{Intermolecular distance $(\mathrm{L})=0.74 \mathrm{~nm}$}

Fig. 8 Formulas and image diagram of intermolecular distance of modifiers (The sample whose amounts of surface modifier groups is $1.8-\mathrm{OR} / \mathrm{nm}^{2}$ ). 

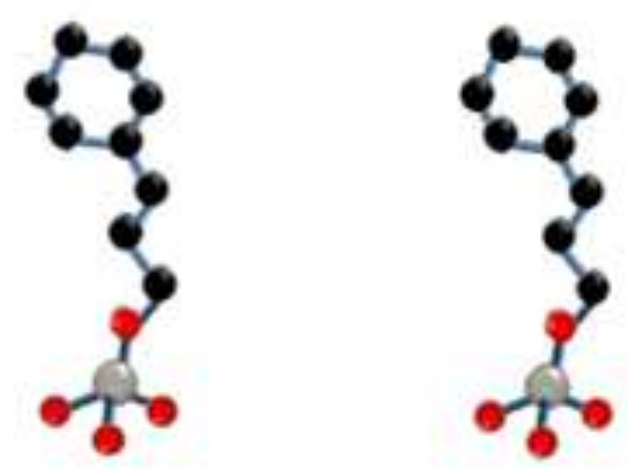

monomer

$\downarrow h v$

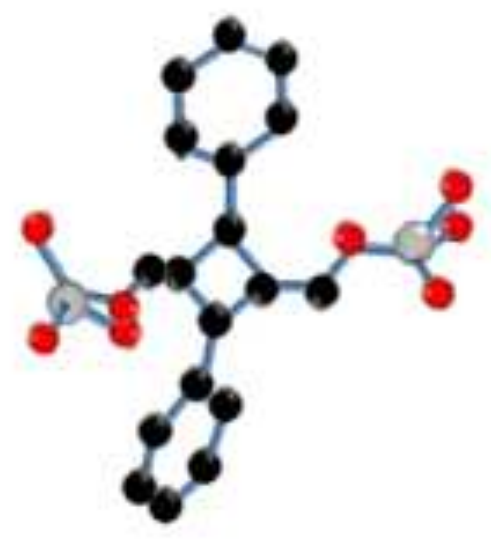

$\alpha$-dimer

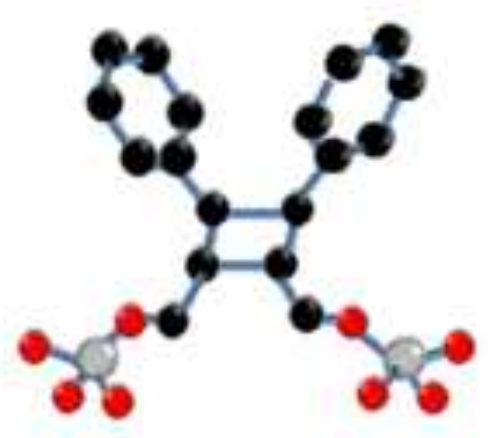

$\beta$ - dimer

Fig. 9 The structure of monomer and $\alpha, \beta$-dimers of cinnamyl alcohol by simulation. 


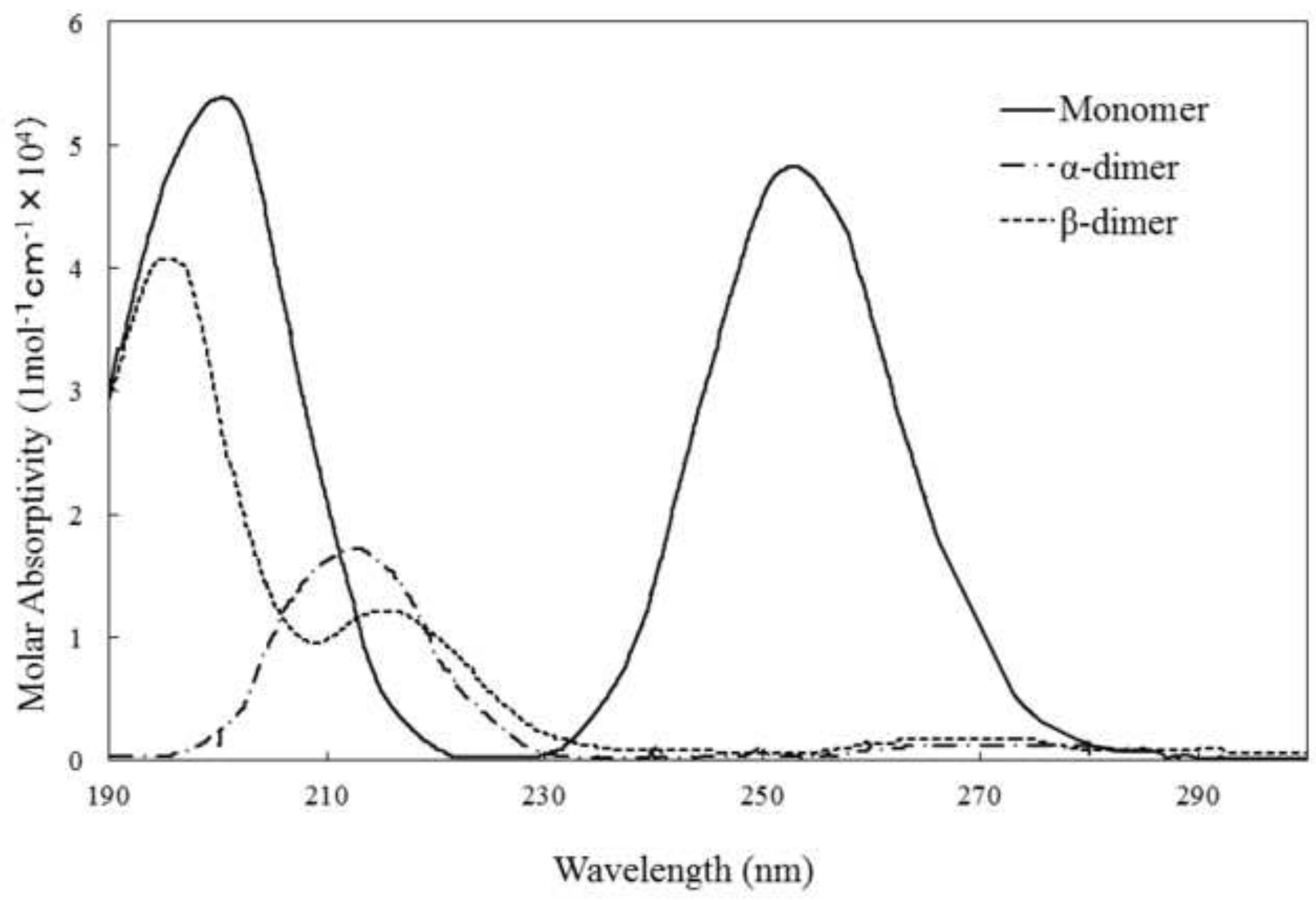

Fig. $10 \mathrm{UV}$ adsorbing spectra of cinnamyl alcohol by simulation. 


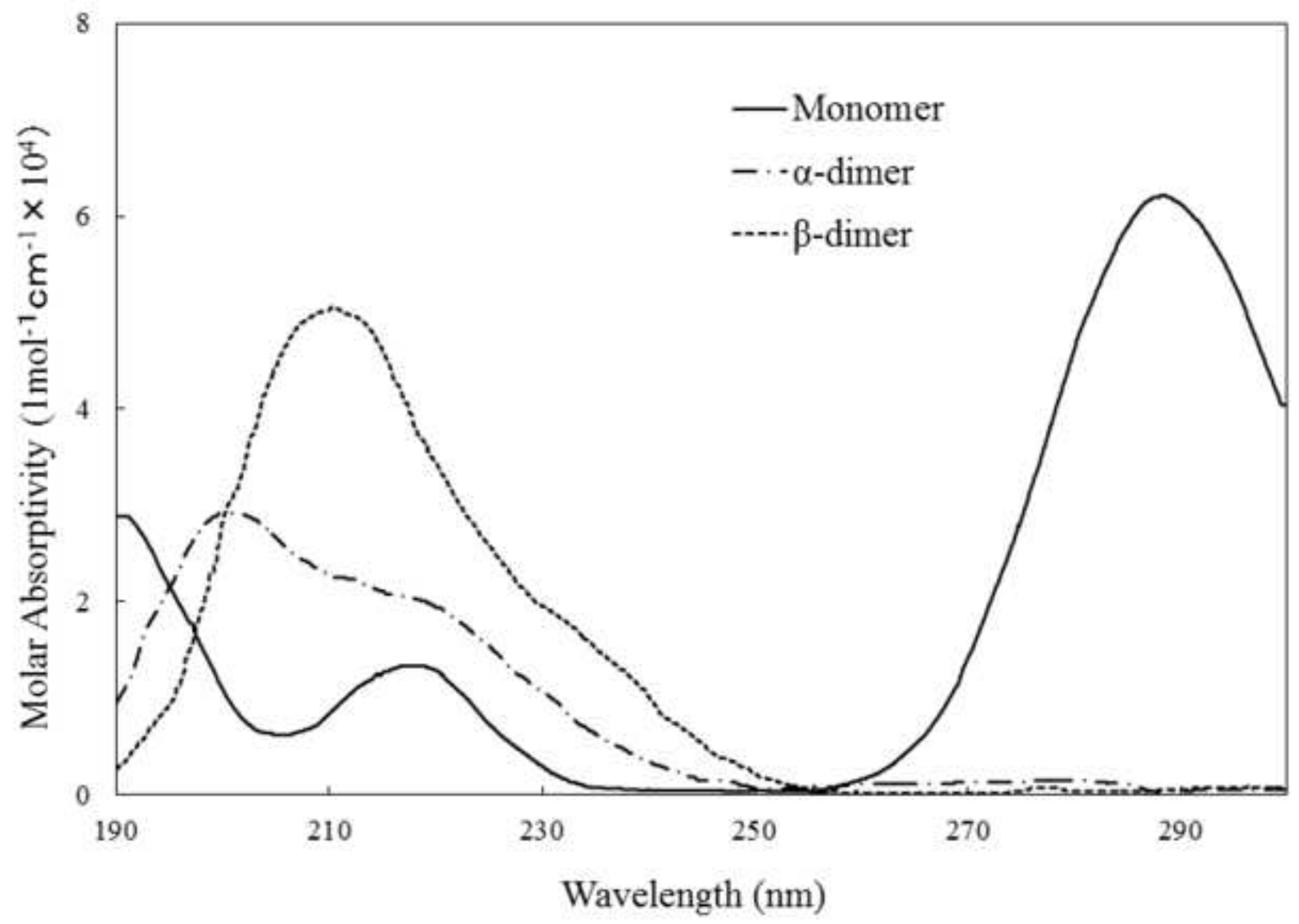

Fig. $11 \mathrm{UV}$ adsorbing spectra of cinnamoyl chloride by simulation. 


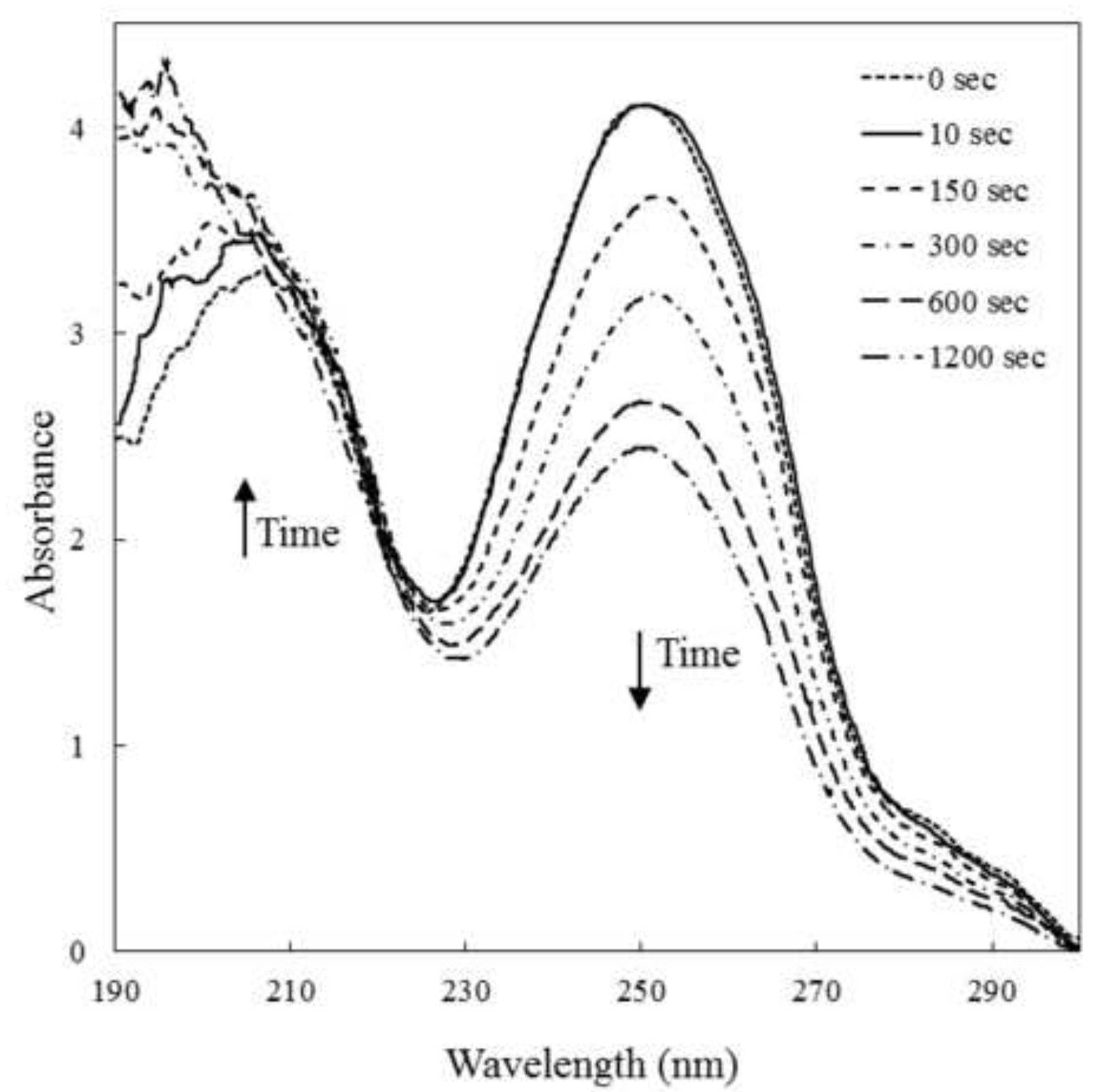

Fig. $12 \mathrm{UV}$ absorbing spectrum change of modifier in organic solvent. 


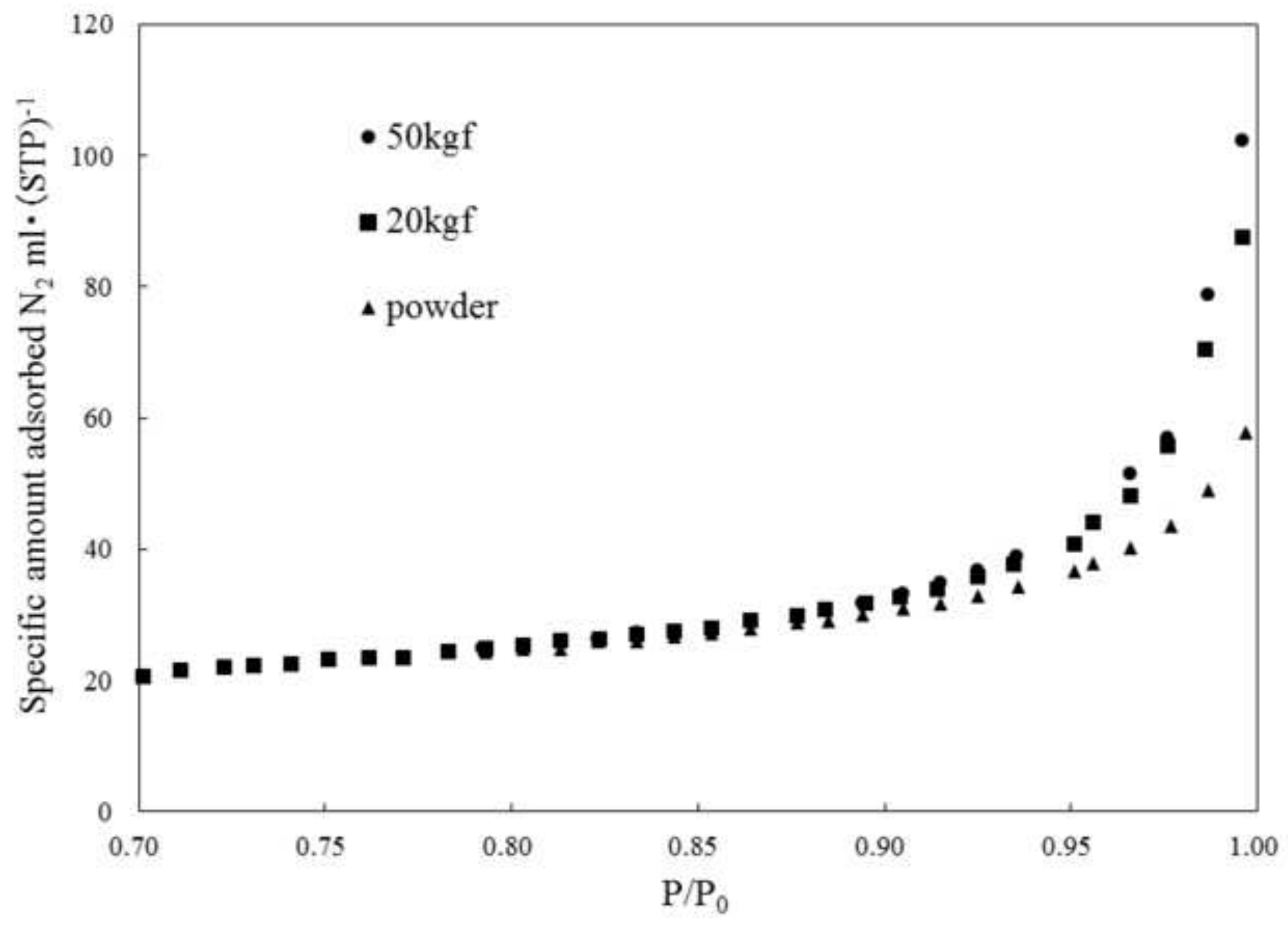

Fig. 13 The adsorption isotherm by nitrogen adsorption. 


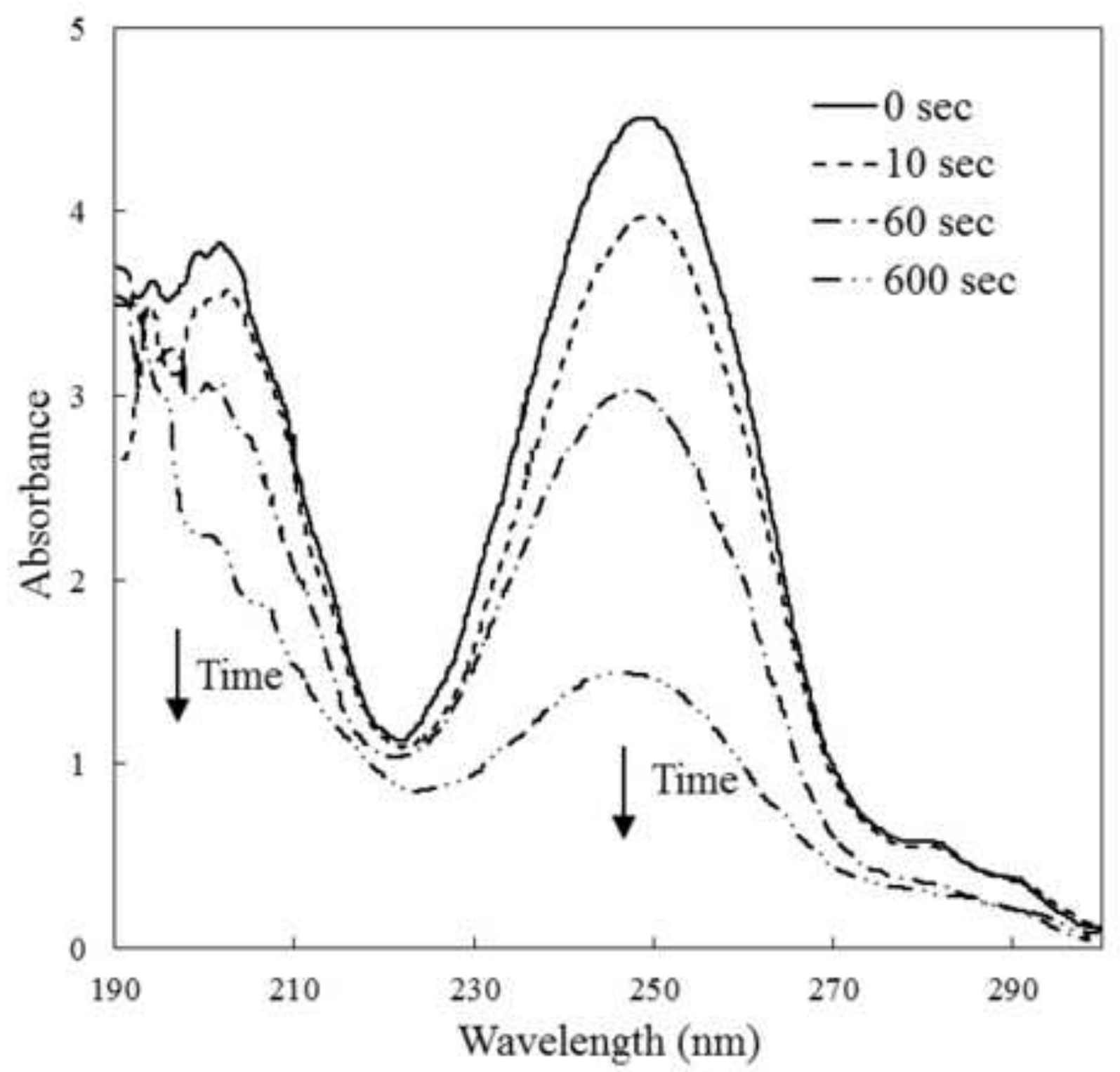

Fig. $14 \mathrm{UV}$ absorbing spectrum change of modified sample of $0.4-\mathrm{OR} / \mathrm{nm}^{2}$ modification density. 


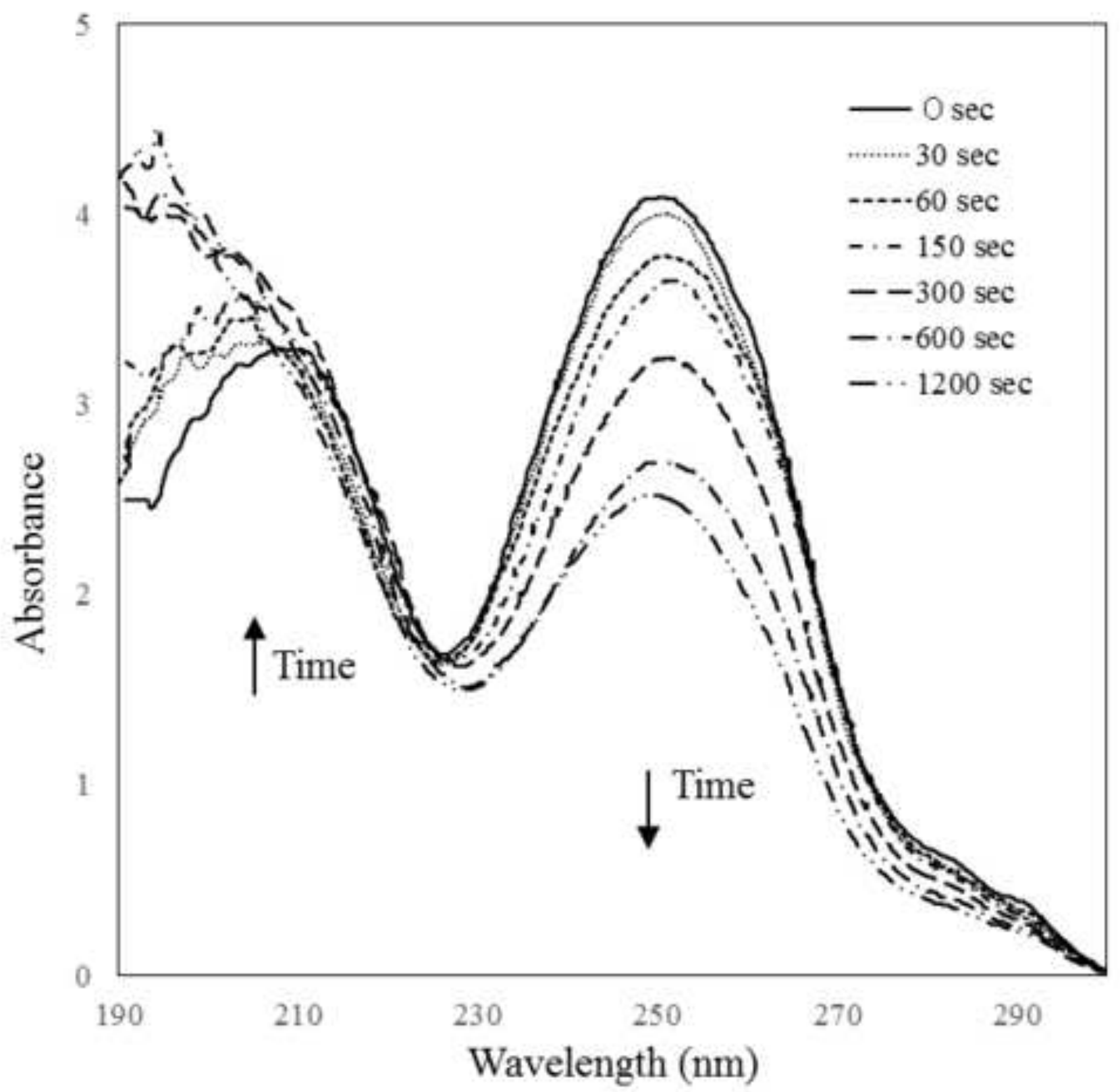

Fig. 15 UV absorbing spectrum change of modified sample of $1.8-\mathrm{OR} / \mathrm{nm} 2$ modification density. 
$\star$ It is formed only between different particle

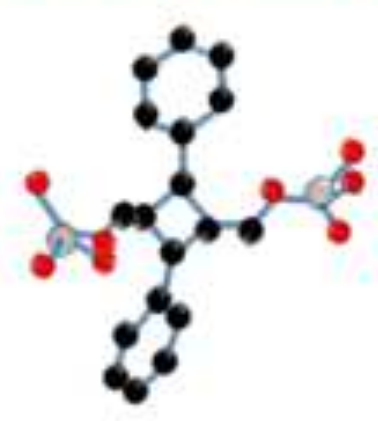

a-dimer

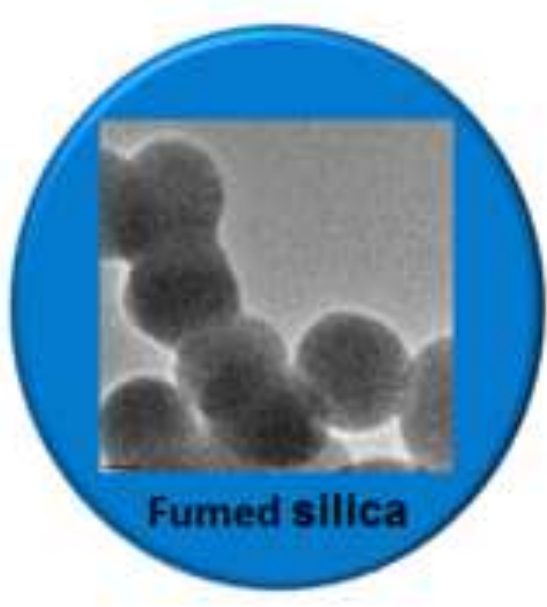

Surface modification With

cinnamyl alcohol or cinnamoyl chloride

It can be formed

between same particle

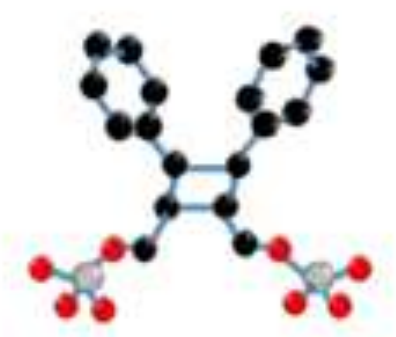

$\beta$-dimer

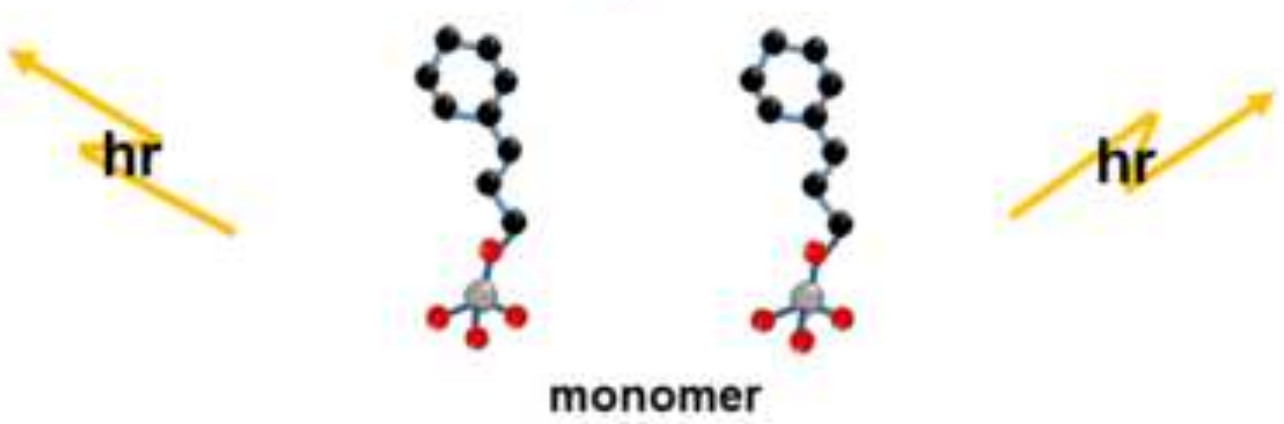

